\title{
Quality of life in arthritis patients using nonsteroidal anti-inflammatory drugs
}

\author{
Ingela Wiklund $\mathrm{PhD}$
}

I Wiklund. Quality of life in arthritis patients using non-steroidal anti-inflammatory drugs. Can J Gastroenterol $1999 ; 13(2): 129-133$. Arthritis is a painful and disabling condition. To suppress the pain and the inflammatory process, patients are often chronic nonsteroidal anti-inflammatory drug (NSAID) users. Chronic use of NSAIDs may induce peptic ulcer, dyspeptic problems and heartburn. Therefore, these patients are often provided with treatment to relieve and/or protect against gastrointestinal problems. Rheumatic disorders also affect a range of healthrelated quality of life domains. In one study, patients with NSAID. associated gastroduodenal lesions complained about lack of energy, sleep disturbances, emotional distress and social isolation in addition to pain and mobility limitations. The degree of distress and dysfunction differed markedly from scores in an unselected population. Clinical trial data suggest that acid-suppressing therapy with omeprazole is superior to therapy with misoprostol and ranitidine in healing gastroduodenal lesions and preventing abdominal pain, heartburn and indigestion symptoms during continued NSAID treatment. Because arthritic patients are severely incapacitated by their condition regarding most aspects of healthrelated quality of life, it is important to offer a treatment that is effective in healing and preventing NSAID-induced ulcers and gastrointestinal symptoms during continued NSAID treatment without further compromising the patients' quality of life. Treatment with omeprazole once daily has been shown to be superior to that with ranitidine and misoprostol in this respect.

Key Words: Arthritis, Misoprostol, Nonsteroidal anti-inflammatory drugs, Omeprazole, Quality oflife, Ranitidine

A rthritis and musculoskeletal disorders are among the most common chronic conditions in adults in developed countries $(1,2)$. American data indicate that $15 \%$ of the noninstitutionalized population reported arthritis with an increasing prevalence with increasing age. Osteoarthritis is estimated to affect more than $10 \%$ of the population over the age of 65 years and is one of the most common reasons why patients consult a family practitioner $(3,4)$.

\section{La qualité de vie des patients arthritiques traités aux anti-inflammatoires non stéroïdiens}

RÉSUMÉ : L'arthrite est une maladie douloureuse et invalidante. Pour supprimer la douleur et enrayer le processus inflammatoire, les patients font souvent appel aux anti-inflammatoires non stéroïdiens en traitement prolongé. L'emploi prolongé d'AINS peut provoquer des ulcères gastro-intestinaux, des problèmes dyspeptiques et des brûlures d'estomac. Par conséquent, beaucoup de ces patients reçoivent également des traitements qui les soulageront ou les protégeront contre les problèmes gastro-intestinaux. Les troubles rhumatismaux affectent également plusieurs aspects de la qualité de vie. Dans le cadre d'une étude, des patients présentant une atteinte gastro-duodénale associée aux AINS se plaignaient de manque d'énergie, de troubles du sommeil, de détresse émotionnelle et d'isolement social, en plus des limites causées par la douleur et de l'immobilité. Ce degré de détresse et de dysfonction différait nettement des indices relevés auprès d'une population non sélectionnée. Selon des essais cliniques, le traitement anti-acide à l'oméprazole est supérieur au traitement au misoprostol et à la ranitidine pour soulager les lésions gastro-duodénales et prévenir la douleur abdominale, les brûlures d'estomac et les symptômes d'indigestion durant le traitement prolongé aux AINS. Étant donné que les patients arthritiques présentent une invalidité sévère en raison de leur maladie et que cela affecte beaucoup leur qualité de vie, il est important de leur offrir un traitement qui soit efficace à guérir et à prévenir les ulcères provoqués par les AINS et les symptômes gastro-intestinaux lors d'un traitement prolongé aux AINS sans compromettre davantage leur qualité de vie. Le traitement à l'oméprazole une fois par jour s'est révélé supérieur au traitement à la ranitidine et au misoprostol à cet égard.

Department of Public Health and Primary Health Care, The University of Bergen, Bergen, Norway; Quality of Life Research, Astra Hässle AB, Mölndal, Sweden

Correspondence and reprints: Professor Ingela Wiklund, Quality of Life Research, Astra Hässle AB, S-431 83 Mölndal, Sweden.

Telephone 46-31-776-1097, fax 46-31-776-38-05, e-mail ingela.wiklund@hassle.se.astra.com 
tween quality of life and markers of disease activity such as rheumatic factor or ery throcyte sedimentation rate is poor to nonexistent (6). Therefore, other outcomes of importance to patients that address pain, disability, emotional distress, and physical and social functioning are increasingly being assessed. It has been suggested that the development of international consensus regarding the importance of an impaired quality of life in arthritis and related disorders should be initiated (8). Others propose that randomized clinical trials in arthritis should ideally use validated quality of life instruments along with clinical end-points (5).

Clinicians are realizing that it is important to understand the full implications of suffering from a chronic condition from the patient's perspective. Health-related quality of life outcomes provide an effective means for clinicians to make clinically sensible decisions by providing further insight into the benefits and drawbacks of treatment options. Such information may also serve as a viable tool when optimizing treatment strategies and facilitating the allocation of medical care resources among different patient populations in a cost effective way.

The majority of patients with arthritis use nonsteroidal anti-inflammatory drugs (NSAIDs) to relieve pain and inflammation. A secondary benefit of the drugs is that patients can maintain normal daily function. Unfortunately, NSAID therapy is not without risks; these agents are well known to cause damage to the gastric and duodenal mucosa leading to ulceration, as well as to cause potentially life-threatening complications such as bleeding and perforation $(9,10)$. Many studies have shown that ulcer disease is associated with upper abdominal pain, heartburn or acid regurgitation, and indigestive problems. One specific problem with NSAID-associated ulcers is, however, that these often are asymptomatic and present with bleeding or perforation. Current treatments for ulcer healing are not optimal, and prostaglandin analogues may carry the additional disadvantage of inducing further gastric side effects that in turn result in discontinuation of therapy (11).

Virtually no researchers have described the impact of suffering from arthritis and muscoskeletal disorders, or the problems related to the occurrence of NSAID-induced upper gastrointestinal lesions on quality of life. The purpose of the present paper is to describe the burden of illness from the patient's perspective using the pretreatment values derived in conjunction with a clinical trial.

\section{QUALITY OF LIFE ASSESSMENTS WITH PARTICULAR REFERENCE TO ARTHRITIS}

In clinical studies and clinical trials, health-related quality of life is best measured in a scientifically valid and rigorous way by using quality of life questionnaires $(12,13)$. Typically, health-related quality of life questionnaires are selfadministered by the patient and contain a series of questions on various health domains. Questions pertaining to each domain are combined to form scales that represent one aspect of quality of life. The scales are scored and compared with those of either a specific patient group or established norma- tive values to determine the patient's quality of life score relative to those of others for descriptive purposes, or to chart progress with a particular therapy. Basically, there are two different kinds of measures for the assessment of quality of life, ie, generic and disease-specific questionnaires (14). Generic measures have been designed primarily for descriptive purposes to delineate the full impact of a disease or its symptoms as comprehensively as possible. In contrast, the specific measures have been developed to monitor the response to treatment of a particular disease entity or condition. The generic measures are applicable to a wide range of populations, whereas the specific ones, by definition, are confined to addressing the problems of selected patient groups. The main advantages of the generic measures are their broad coverage and that they allow comparisons of different patient populations; however, generic measures are less responsive to treatment-induced change when used in clinical trials. Irrespective of whether a generic or disease-specific measure is employed, the use of internationally available, standard scales ensures that the psychometric properties of measures are well established. Among the psychometric properties, responsiveness, ie, the ability of a measure to detect small treatment-induced changes over time, and clinical relevance are the crucial features (15). Among generic instruments, which include health profiles and utility measures, the Short Form 36 and the Nottingham Health Profile (NHP) have previously been used in patients with arthritis $(5,7,16)$. Utility measures have been infrequently used in arthritis. There are several disease-specific measures designed to delineate the suffering of patients with arthritis. The Arthritis Impact Measurement Scale and the Health Assessment Questionnaire are examples of commonly used disease-specific questionnaires $(5,7)$.

\section{QUALITY OF LIFE IN PATIENTS USING NSAIDS}

Patients: Patients in the present study were included in a clinical trial primarily aimed at comparing an antisecretory strategy using the acid pump inhibitor omeprazole with a cytoprotective strategy using misoprostol in patients taking NSAIDs on a long term basis (17).

Methods: Before starting treatment, the patients completed three validated quality of life questionnaires, the NHP (18), the Psychological General Well-Being (PGWB) index and the Gastrointestinal Symptom Rating Scale (GSRS) (19). In addition, a short scale was used to address joint-specific problems.

The NHP measures the perceived impact of chronic disease and has been extensively tested for reliability and validity (18). The NHP consists of two parts. In part I, the degree of distress and dysfunction is evaluated within six dimensions descriptive of problems with energy, sleep, social isolation, pain, emotions and physical mobility using 38 yes or no questions. Part II of the NHP contains seven yes or no statements referring to health-related problems within areas relating to paid employment, housework, social life, home life, sex life, hobbies and holidays. The higher the score, the worse the patient. 


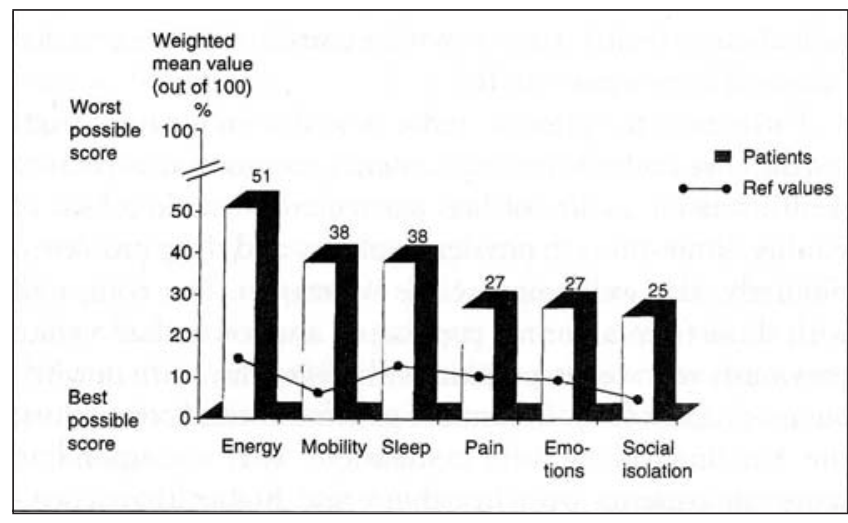

Figure 1) Health-related quality of life in patients with arthritis (n=691). The Nottingham Health Profile (Part I). Ref Reference. Adapted from reference 21

The PGWB index includes 22 items that, as well as providing an overall score, evaluate six separate dimensions: anxiety, depression, positive well-being, self-control, general health and vitality (20). The subscales used to measure these six states have three to five items, each using a six-point Likert scale. In the PGWB, the higher the value, the better the patient's perceived well-being.

Arthritis-related disability was captured by questions evaluating ability to write, shower, button articles of clothing and use the toilet, and morning stiffness and joint pain. The higher the value, the more pronounced the patient's problem.

The GSRS is a self-administered questionnaire that evaluates 15 gastrointestinal symptoms (19). Rather than addressing the severity or frequency of symptoms, patients are asked how bothered they are, ie, what is the degree of discomfort induced by symptoms on a seven-point Likert scale (no, minor, mild, moderate, moderately severe, severe or very severe discomfort). The GSRS contains a total score and five individual dimensions describing indigestion (excess gas, eructation, bloating, borborygmus), diarrhea (increased passage of stools, loose stools, urgent need for defecation), constipation (decreased passage of stools, hard stools, incomplete evacuation), abdominal pain (abdominal pain, nausea, sucking sensations) and reflux (heartburn, acid regurgitation). In the GSRS, the lower the value, the less the perceived gastrointestinal discomfort.

Results: A total of 693 patients participated in the quality of life evaluation, of whom $59 \%$ were women. The mean age was $59 \pm 12$ years. Fifty per cent of the patients suffered from osteoarthritis, $37 \%$ had rheumatoid arthritis, $11 \%$ had other arthritic conditions and $2 \%$ had a combination of these diagnoses. Twenty-seven per cent of the patients had peptic ulcer, a significant number had gastric or duodenal erosions, and $33 \%$ were Helicobacter pylori-positive. A history of previous dyspeptic symptoms was found in $77 \%$.

Patients with arthritis generally have a poor quality of life, as measured by the NHP part I, compared with reference values derived in a general population sample (21) (Figure 1). This was particularly evident in terms of lack of energy, sleep disturbances and physical mobility limitations. In part II of

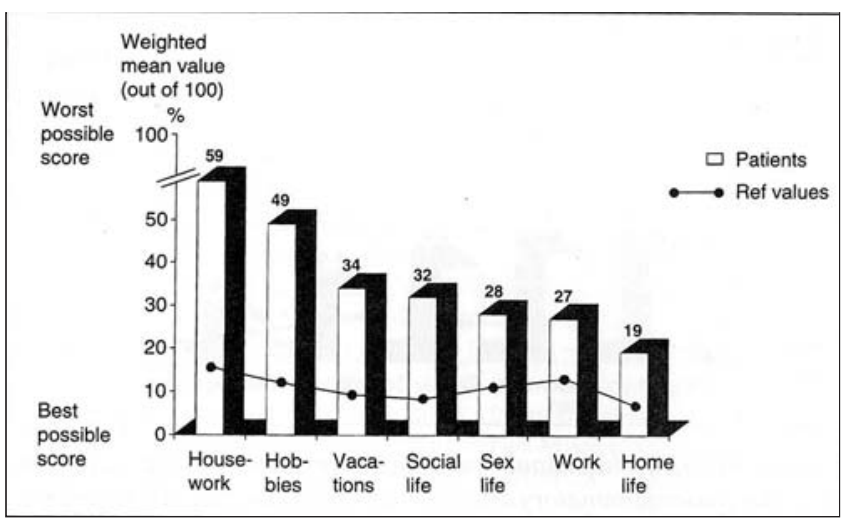

Figure 2) Health-related quality of life in patients with arthritis ( $n=691)$. The Nottingham Health Profile (Part II). Ref Reference. Adapted from reference 21

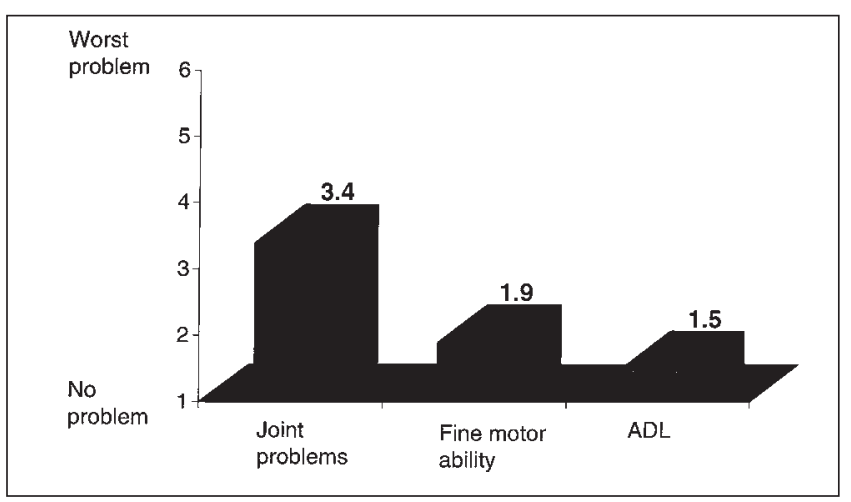

Figure 3 ) Rheumatoid arthritis-specific distress and dysfunction. $A D L$ Activities of dally life

the NHP, patients had heal th-related problems in areas such as inability to do housework and hobbies (Figure 2). The adverse impact on social function was also prominent.

Assessed in the PGWB index, well-being was severely compromised in patients with arthritis. The mean value of well-being scores was 92 , which is similar to the mean value of 91 observed in patients with angina pectoris waiting for coronary artery bypass surgery (22), and much lower than the mean value of 103 observed in a normal healthy population (23).

The degree of arthritis-specific distress and disability was moderate according to the disease-specific questions and was most pronounced in joint-related problems (Figure 3). Activities of daily living were the least affected area.

Patients reported moderate or severe symptoms, ie, of a magnitude that they interfered with the ability to perform daily activities. The distress was most pronounced for indigestion and abdominal pain (Figure 4), but patients also had heartburn symptoms. Gastrointestinal symptoms from the lower gastrointestinal tract were less frequent.

\section{DISCUSSION}

In arthritis, there has been a shift from reliance on clinical measurements that are primarily focused on the assessments of articular status or laboratory measures to aspects that are of direct importance to the patient. Because less attention 


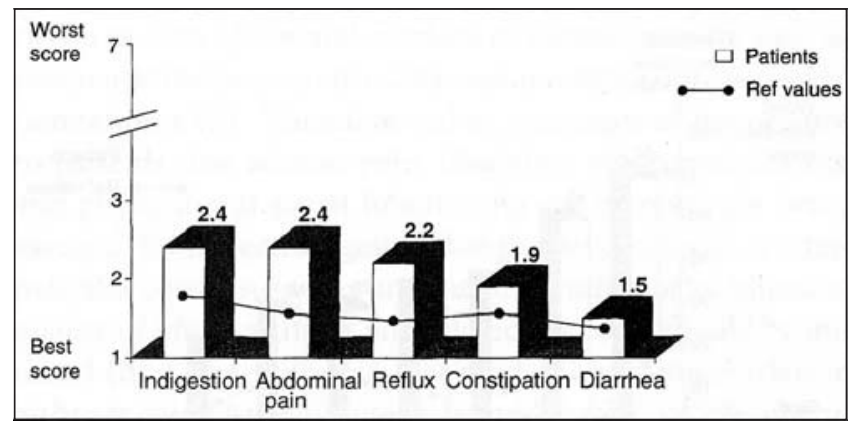

Figure 4) Gastrointestinal symptoms in arthritis patients with nonsteroidal anti-inflammatorydrug-induced gastriclesions. Ref Reference. Adapted from reference 23

has been given to determining the overall impact of the condition on the patient's welfare, there seems to be an overall need to capture how arthritis affects patient's health-related quality of life by going beyond the handicap, disability and impairment and asking patients what they are prevented from doing and how they react emotionally to these restrictions. Quality of life is sometimes not felt to be an issue for the busy and clinically oriented doctor. However, the benefits of open communication between a patient and a clinician can lead to concrete measures that can be tailored to meet the patient's needs, depending on the responses to a brief questionnaire. This opportunity for an exchange between patient and doctor is of value in treating long term and debilitating chronic conditions.

The emerging need among clinicians to capture patientbased outcomes was recently highlighted in the report from the first World Health Organization and International League of Association for Rheumatology Taskforce on impaired quality of life from rheumatic diseases (24). Survey data indicate that patients desire most of all to function normally and to be free of pain, and other physical, psychological or social symptoms. Other important issues pertain to being free of iatrogenic problems induced by the treatment, to have healthy finances after medical expenses and to live as long as possible (25).

The techniques for measuring quality of life are well accepted, having been validated by more than 30 years of research, and are currently being applied in a number of clinical research areas. The methods are sufficiently advanced to contribute to an understanding of the effects of medical treatment. Today, quality of life assessments are often desired by decision makers because they provide physicians, patients and society with more complete information regarding the benefits and risks of medical treatment in terms of patient physical, psychological, and social functioning and well-being. Finally, quality of life assessments can contribute to defining health outcomes in cost effectiveness analyses.

The reason why NHP was chosen to indicate the burden of illness in this study was that NHP was available in most of the languages relevant to the study and, moreover, had been used previously to describe and evaluate the impact of therapy in patients with arthritis (16). Another study recently corroborated that NHP provides clinically relevant informa- tion about arthritis patients with a correlation between distress and disease activity (6).

Patients in the present study, as well as in previous studies, displayed significant impairment in terms of all aspects of health-related quality of life, particularly regarding lack of vitality, limitations in physical mobility and sleep problems. Similarly, the well-being scores were quite low compared with those from a normal population and lower than values previously reported in patients with heartburn, with or without esophagitis (26). In terms of gastrointestinal complaints, the baseline values were compatible with corresponding scores in patients with heartburn and higher than corresponding scores in a reference population (23). The jointspecific dysfunction was rather modest, and this was likely a result of continual use of NSAIDs. Previous quality of life studies in patients with arthritis have shown that somatic complaints, activity limitations and satisfaction with current life situation were the most frequently reported factors (27).

Compared with diabetes, hypertension, pulmonary disease, cancer and cardiac disease, arthritis was found to be associated with the most negative health status and ranked as one of the most morbid chronic diseases (28). Stewart et al (29) compared health-related quality of life in different chronic diseases such as rheumatoid arthritis, hypertension, myocardial infarction, congestive heart failure and gastrointestinal disorders, and related the degree of distress and dysfunction to the level observed in a healthy population. A significant negative effect was observed on most measures of functioning and well-being for all conditions except hypertension. Interestingly, patients with gastrointestinal disorders scored lower than patients with all other conditions in terms of social functioning, health perceptions and mental health, whereas arthritis patients had the lowest scores in bodily pain.

Marked improvements in quality of life are well recognized to occur when arthritic patients take NSAIDs; however, NSAID-induced gastrointestinal events, ranging from dyspeptic symptoms to severe complications, are serious drawbacks. These events are costly to treat and represent a substantial negative effect on health-related quality of life. Patients tend to place a high value on the avoidance of gastrointestinal complications (30). In one study, preferences of patients with differing severity of ulcer disease were determined to be, in decreasing order, the avoidance of surgery, hospitalization, diarrhea induced by prophylaxis against NSAID-related gastric lesions and uncomplicated ulcer requiring out-patient treatment. In fact, the disutility that patients attached to the adverse effects of diarrhea surprised the investigators (31).

Available treatments such as misoprostol or ranitidine decrease the risk of developing NSAID-associated ulcers but are less effective in doing so and in relieving gastrointestinal symptoms and/or ulcer healing compared with omeprazole (17). Furthermore, there is clear evidence that patients may be compromised because of the adverse effects, specifically diarrhea, associated with medications such as misoprostol. Few studies have addressed the adverse effects of medication 
on quality of life. However, it has been shown that prophylaxis with misoprostol results in modest additional costs and provides no additional quality of life benefits, primarily owing to the increase in diarrhea associated with misoprostol (32). Treatment with misoprostol results in a higher incidence of gastrointestinal side effects than that with ranitidine (33) and omeprazole (17) in patients with NSAID. induced ulcers. In fact, in patients with multiple risk factors, the gain in quality of life by avoidance of gastric ulcers seems to offset the loss in quality of life caused by diarrhea, the most important misoprostol side effect (34).

The results of the present study showed that omeprazole in combination with NSAIDs was capable of healing and preventing gastric and duodenal lesions, and the associated gastrointestinal symptoms. Importantly, the cost effectiveness of using omeprazole compared with misoprostol was also corroborated (35).

\section{CONCLUSIONS}

Patients with arthritis using NSAIDs have a poor healthrelated quality of life. Treatment of NSAID-induced gastric and duodenal lesions in these patients, who often are already severely compromised, represents the worst case scenario if the treatment is accompanied by adverse events because they may lead to noncompliance or cessation of NSAID therapy. A treatment that effectively heals and prevents upper gastrointestinal lesions and associated dyspeptic symptoms without side effects allows continued NSAID therapy and, thereby, optimizes the patient's quality of life.

\section{REFERENCES}

1. Badley EM, Thompson RP, Wood PHN. The prevalence and severity of major disabling conditions - a reappraisal of the government social survey on the handicapped and impaired in Great Britain. Int J Epidemiol 1978;7:145-51.

2. Arthritis prevalence and activity limitations - United States, 1990. MMWR Morb Mortal Wkly Rep 1994:43:433-8.

3. Brandt KD, Dieppe P, eds. Management of Pain in Osteoarthritis: Current approaches. Drugs 1996:52(Suppl 3).

4. Cunningham LS, Kelsey JL. Epidemiology of muscoloskeletal impairments and associated disability. Am J Public Health $1984 ; 74: 574.9$.

5. Cheah SY, Clark C, Goldberg L, Li Wan Po A, Phillips R. Outcome measures, pooled index and quality of life instruments in rheumatoid arthritis. J Clin Pharm Ther 1996;21:297-316.

6. Houssien DA, McKenna SP, Scott DL. The Nottingham Health Profile as a measure of disease activity and outcome in rheumatoid arthritis. Br J Rheumatol 1997;36:69-73.

7. Tuttleman M, Pillemer SR, Tilley BC, et al. A cross sectional assessment of health status instruments in patients with rheumatoid arthritis participating in a clinical trial. Minocycline in Rheumatoid Arthritis Trial Group. J Rheumatol 1997;24:1910.5.

8. Morales-Torres J, Reginster JY, Hochberg MC. Rheumatic and musculoskeletal diseases and impaired quality of life: a challenge for rheumatologists. J Rheumatol 1996;23:1-3.

9. Fries JF, Williams CA, Bloch DA. The relative toxicity of nonsteroidal antiinflammatory drugs. Arthritis Rheum $1991 ; 34: 1353-60$.

10. Somerville K, Faulkner G, Langman M. Non-steroidal antiinflammatory drugs and bleeding peptic ulcer. Lancet 1986;1:462-4.

11. La Montagna G, Tirri G, Cacace E, et al. Quality of life assessment during six months of NSAID treatment. Clin Exp Rheumatol $1998 ; 16: 49-54$.

12. Cox DR, Fitzpatrick R, Fletcher AE, Gore SM, Spiegelhalter DJ, Jones DR. Quality of life assessment: Can we keep it simple? J R Stat Soc A $1992 ; 155 \div 353-93$.
13. Fitzpatrick R, Fletcher A, Gore S, Jones D, Spiegelhalter D, Cox D. Quality of life measures in health care. I: Applications and issues in assessment. BMJ 1992:305:1074-7.

14. Guyatt GH, Veldhuyzen Van Zanten SJ, Feeny DH, Patrick DL. Measuring quality of life in clinical trials: a taxonomy and review. Can Med Assoc J 1989;140:1441-8.

15. Fitzpatrick R, Ziebland S, Jenkinson C, Mowat A, Mowat A. Importance of sensitivity to change as a criterion for selecting health status measures. Qual Health Care 1992;1:89-93.

16. Parr G, Darekar B, Fletcher A, Bulpitt CJ. Joint pain and quality of life; results of a randomised trial. Br J Clin Pharmacol 1989;27:235-42.

17. Hawkey CJ, Karrasch JA, Szczepanski L, et al. Omeprazole compared with misoprostol for ulcers associated with nonsteroidal antiinflammatory drugs. Omeprazole versus Misoprostol for NSAID-induced ULcer Management (OMNIUM) Study Group. $\mathrm{N}$ Engl J Med 1998;338:727-34.

18. Dimenäs E, Glise H, Hallerbäck B, Hernqvist H, Svedlund J, Wiklund I. Well-being and gastrointestinal symptoms among patients referred to endoscopy owing to suspected duodenal ulcer. Scand J Gastroenterol 1995;30:1046-52.

19. Hunt S, McEwen J, McKenna S. Measuring Health Status. London: Croom Helm, 1986.

20. Dupuy HJ. The Psychological General Well-Being (PGWB) index. In: Wenger NK, Mattson ME, Furberg CF, Elinson J, eds. Assessment of Quality of Life in Clinical Trials of Cardiovascular Therapies. New York: Le Jacq Publishing Inc, 1984:170-83.

21. Hunt SM, McEwen J, McKenna SP. Perceived health: age and sex comparisons in a community. J Epidemiol Community Health $1984 ; 38: 156-60$

22. Sjöland H, Caidahl K, Wiklund I, et al. Impact of coronary artery bypass grafting on various aspects of quality of life. Eur J Cardiothorac Surg 1997;12:612-9.

23. Dimenäs E, Carlsson G, Glise H, Israelsson B, Wiklund I. Relevance of norm values as part of the documentation of quality of life instruments for use in upper gastrointestinal disease. Scand J Gastroenterol Suppl 1996;221:8-13.

24. Strand V, Russell AS. WHO/ILAR Taskforce on quality of life. J Rheumatol 1997;24:1630.3.

25. Potts MK, Mazzuca SA, Brandt KD. Views of patients and physicians regarding the importance of various aspects of arthritis treatment. Correlations with health status and patient satisfaction. Patient Educ Couns $1986 ; 8: 125-34$.

26. Wiklund I, Bardhan KD, Müller-Lissner S, et al. Quality of life during acute and intermittent treatment of gastroesophageal reflux disease with omeprazole compared with ranitidine. Results from a multicentre clinical trial. The European Study Group. Ital J Gastroenterol Hepatol $1998 ; 30: 19-27$.

27. Bendtsen P, Hörnquist JO. Change and status in quality of life in patients with rheumatoid arthritis. Qual Life Res 1992;1:297-305.

28. Mason JH, Weener JL, Gertman PM, Meenan RF. Health status in chronic disease: a comparative study of rheumatoid arthritis. J Rheumatol 1983;10:763-8.

29. Stewart AL, Greenfield S, Hays RD, et al. Functional status and well-being of patients with chronic conditions. Results from the Medical Outcomes Study. JAMA 1989;262:907-13.

30. Fries JF. Quality of - life considerations with respect to arthritis and nonsteroidal anti-inflammatory drugs. Am J Med 1998;104:14S-20S.

31. Gabriel SE, Campion ME, O'Fallon WM. Patient preferences for nonsteroidal antinflammatory drug related gastrointestinal complications and their prophylaxis. J Rheumatol 1993;20:358-61.

32. Gabriel SE, Campion ME, O'Fallon WM. A cost-utility analysis of misoprostol prophylaxis for rheumatoid arthritis patients receiving nonsteroidal anti-inflammatory drugs. Arthritis Rheum $1994 ; 37: 333-41$.

33. Raskin JB, White RH, Jaszewski R, Korsten MA, Schubert TT, Fort JG. Misoprostol and ranitidine in the prevention of NSAID-induced ulcers: a prospective, double-blind, multicenter study. Am J Gastroenterol 1996;91:223-7.

34. Stucki G, Sangha O, Michel BA. [Is misoprostol effective in NSAID-induced gastrointestinal complications?] Schweiz Med Wochenschr 1996;126:1573-8.

35. Grace EM, Oh P, Wahlqvist P. An economic evaluation of omeprazole compared to misoprostol for the acute treatment and prevention of nonsteroidal anti inflammatory drugs (NSAIDs) associated gastroduodenal ulcers, erosions and symptoms. J Rheumatol 1998;25(Supp1 52):23A. 


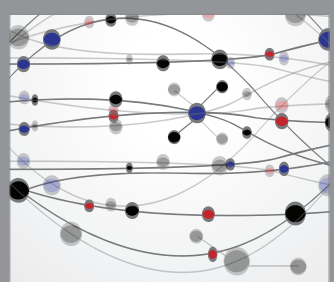

The Scientific World Journal
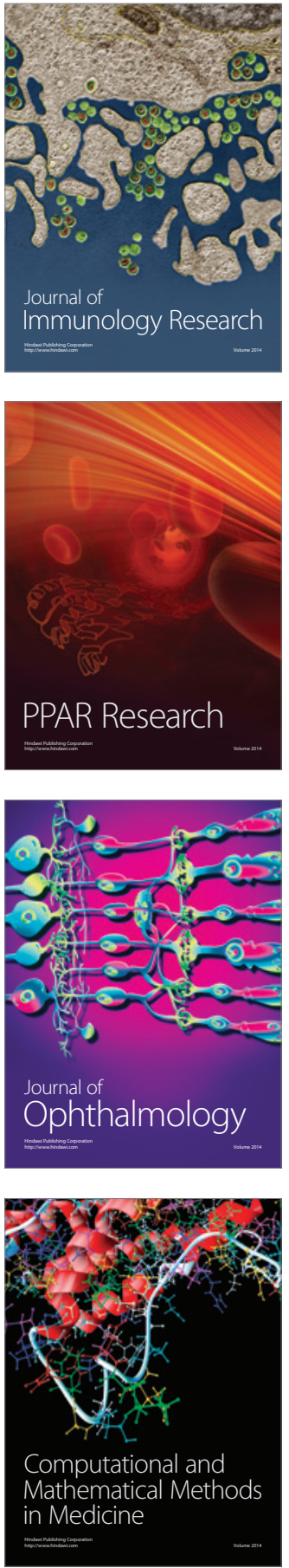

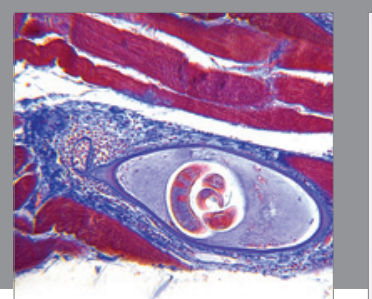

Gastroenterology Research and Practice

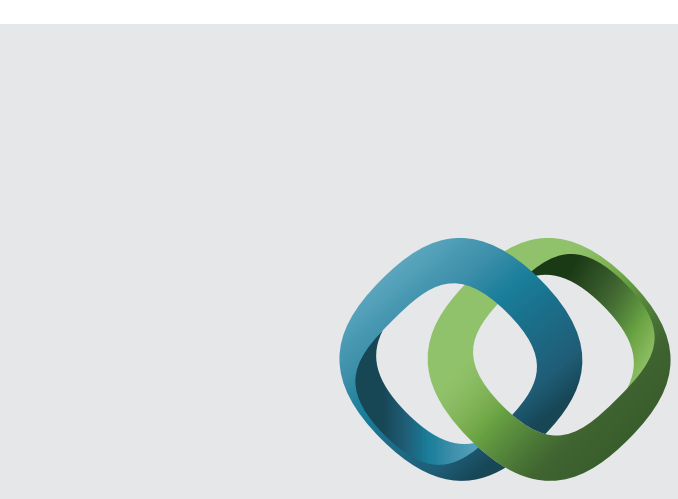

\section{Hindawi}

Submit your manuscripts at

http://www.hindawi.com
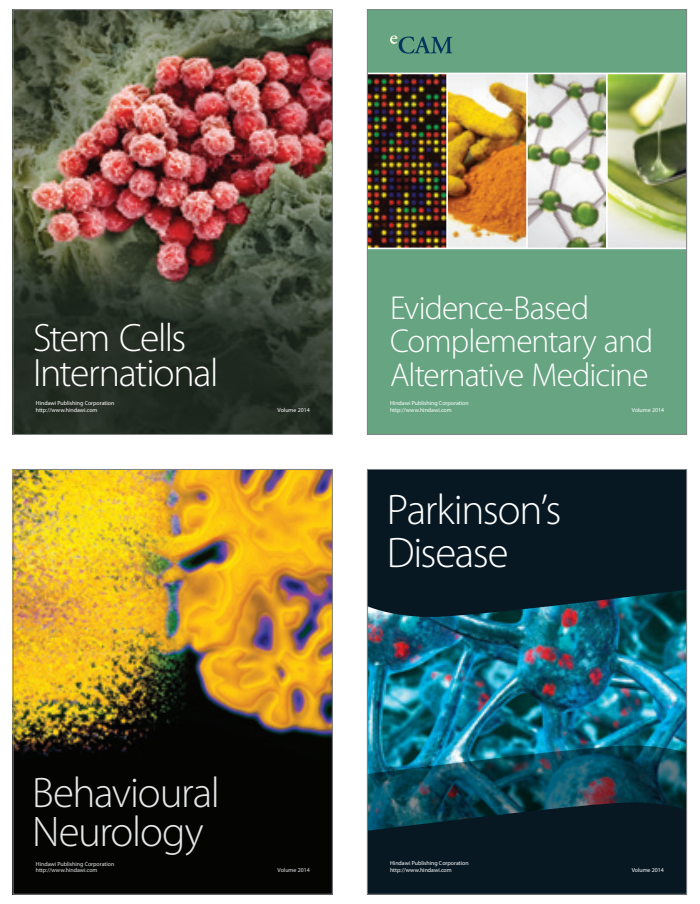
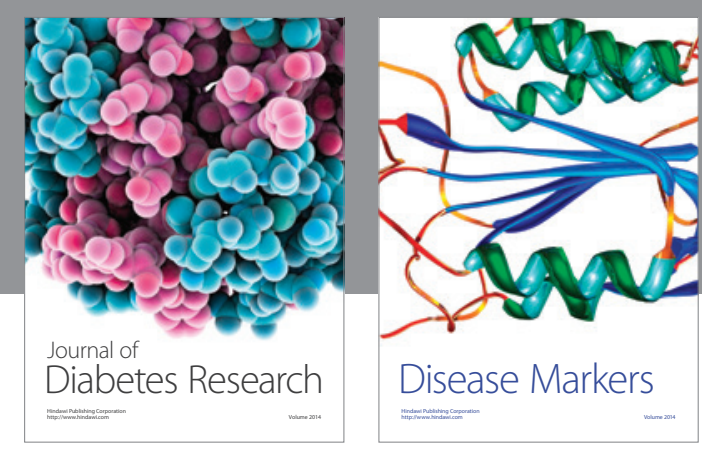

Disease Markers
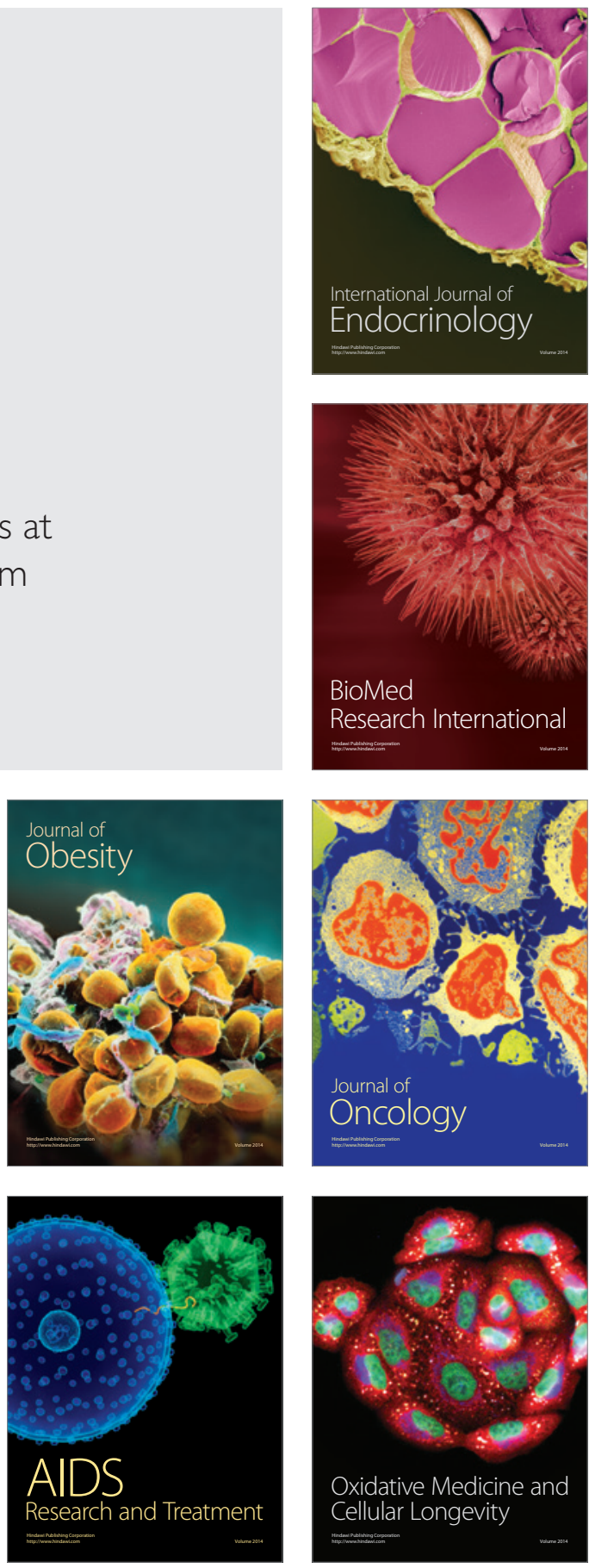